\title{
Medical Organization
}

\section{Use of Intravenous Urography}

\author{
L. KREEL, A. ELTON, R. HABERSHON, A. M. S. MASON, T. W. MEADE
}

British Medical fournal, 1974, 4, 31-33

\section{Summary}

Studies on 1,476 intravenous urographic examinations done in a 15-month period showed that the proportion of abnormal results varied widely-from $20 \%$ in patients with abdominal pain other than renal colic to $92 \%$ of those in prostatism. Patients with the strongest clinical evidence of haematuria were the most likely to have abnormal urograms, and to undergo cystoscopy with abnormal findings on this examination. All six patients with renal hypertension showed abnormalities other than on the urogram. Prior use of other tests may increase the effectiveness of urography.

\section{Introduction}

Requests for radiological investigations have increased by over half ${ }^{1}$ during the past decade, which is disproportionately greater than any increase in staff. ${ }^{2}$ Little information is available on the reasons for or the results of these investigations. The prospect of serious shortages of some key materials used in radiology gives added urgency to the need to make increasingly effective use of this facility.

Ashley et al. ${ }^{1}$ showed large differences in the extent to which radiology was used for different groups of patients with the same diagnosis but did not compare its effects on management. Bull and Zilkha, ${ }^{3}$ in a retrospective study of 200 consecutive outpatients who had no physical signs, showed that most plain skull $x$-ray films taken for migraine, headache, pain in the neck, Parkinsonism, Menière's disease, and epilepsy did not contribute materially to the diagnosis. Atkinson and Kellett ${ }^{4}$ found that as a result of 985 urographic examinations performed on 952 patients with hypertension 39 diagnoses were confirmed and 81 new ones were made. In only nine cases, however, did these findings appear to lead to an alteration in management. Though these authors did not doubt the possibility of detecting treatable renal lesions in patients with hypertension by means of intravenous urography, they questioned whether the frequency with which these abnormalities are found justifies the investigation in all patients with hypertension.

Northwick Park Hospital and Clinical Research Centre, Harrow, Middlesex HA1 3UJ

L. KREEL, F.R.C.P., F.F.R., Consultant Radiologist

A. ELTON, M.S., F.R.C.S., Consultant Surgeon

R. B. HABERSHON, M.B., M.R.C.P., Member of Scientific Staff, Division of Communicable Diseases

A. M. S. MASON, M.B., M.R.C.P., Member of Scientific Staff, M.R.C./ D.H.S.S. Epidemiology and Medical Care Unit

T. W. MEADE, B.M., M.R.C.P., Director, M.R.C./D.H.S.S. Epidemiology and Medical Care Unit
We have studied the uses made of intravenous urography at this hospital to assess the proportions of abnormal urograms requested under different circumstances and to attempt to find ways in which the use of this investigation can be made more effective.

\section{Methods}

The request and result forms for 1,476 intravenous urographic examinations performed during a 15 -month period were reviewed. The total number of patients was 1,$443 ; 25$ underwent urography more than once, and 187 of the requests were made for more than one reason. Apart from the patient's age, sex, and address the information on the forms includes the source of the investigation, the reasons for it, and the result.

Source.-Each form shows the name of the clinician in charge of the case, either a consultant in the case of hospital patients or a general practitioner using the open-access radiology facilities; for hospital patients, status as either inpatient or outpatient is also recorded.

Reasons.-The clinician states his reasons for requesting the investigation. These are usually in the form of symptoms (blood in urine), physical signs (raised blood pressure), or a diagnosis (renal stone).

Result.-The radiologist's report is recorded. An independent doctor classified the reports as follows: (1) normal findings, no abnormality detected; (2) abnormal findings, an abnormality considered relevant to the information on the request formfor example, a report of small, shrunken kidneys after a request because of hypertension. (An abnormal finding defined in these terms does not, however, necessarily imply that the urogram contributed to the patient's management; this point should be borne in mind when considering the results presented below); and (3) incidental findings, an abnormality considered incidental and probably irrelevant to the information on the request form - for example, a report of a bifid ureter after a request because of hypertension. In the following analyses (3) is combined with (1).

The case notes of hospital patients who had undergone urography because of haematuria or hypertension were reviewed by a second doctor who was also independent of the radiological and clinical teams. The case notes of $156(96 \%)$ of the 162 patients with haematuria as the reason for the request were examined, as were the notes of $130(94 \%)$ of the 139 patients with hypertension. The case notes of 65 patients with prostatism were also reviewed.

\section{Results}

Of the 1,476 requests for urograms, 803 (55\%) came from the outpatient department, $520(35 \%)$ were for inpatients, and 153 $(10 \%)$ came from general practice. Most requests $(65 \%)$, therefore, came from the outpatient department and general 
practice. Of all the reasons for the requests seven predominated (table I).

The proportions of abnormal urograms varied widely with the reasons for the investigation and also between the doctors making the requests (table II).

The percentages of abnormal urograms ordered by or on behalf of consultants and general practitioners for four reasons are shown in table III. (The four reasons were chosen because they accounted for $87 \%$ of all requests by general practitioners). Significantly more abnormalities were found in urograms on inpatients than from outpatients or patients referred by general practitioners; this was to be expected.

TABLE I-Reasons Given for Requesting Urograms

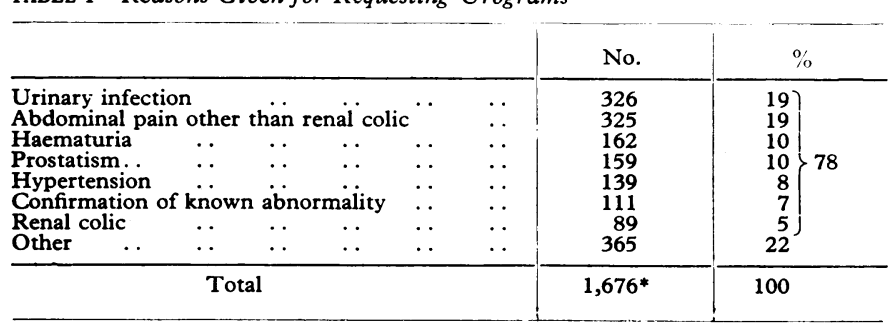

* On 187 request and result forms more than one reason was given.

TABLE II-Percentage of Abnormal Urograms by Reasons Specified for Individual Hospital Consultants and All General Practitioners (Numbers of Urograms are Given in Parentheses)

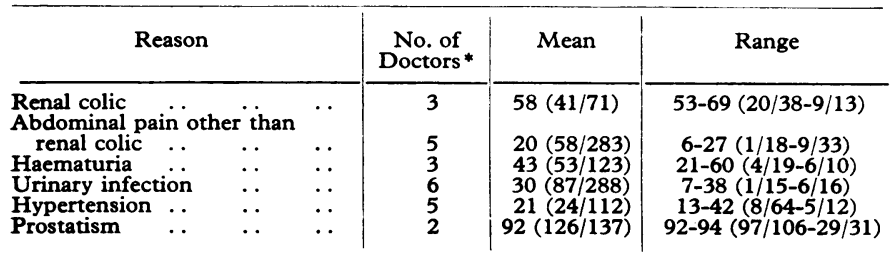

* Hospizal consultants individually, and general practioners collectively, making at least 10 requests for any speciflc reason.

TABLE III-Percentage of Abnormal Urograms by Reasons Specified for All Hospital Consultants (Figures for Outpatients and Inpatients Given Separately) and All General Practitioners (Numbers of Urograms are Given in Parentheses)

\begin{tabular}{c|c|c|c|c}
\hline \multirow{2}{*}{ Reason } & \multicolumn{2}{|c|}{ Hospital Consultants } & $\begin{array}{c}\text { General } \\
\text { Practitioners }\end{array}$ & Total \\
\cline { 2 - 3 } & Inpatients & Outpatients & & \\
\hline $\begin{array}{c}\text { Renal colic ... } \ldots \\
\text { Abdominal pain other } \\
\text { than renal colic } \ldots\end{array}$ & $65(22 / 34)$ & $46(16 / 35)$ & $60(12 / 20)$ & $56(50 / 89)$ \\
$\begin{array}{c}\text { Haematuria } \\
\text { Urinary infection } \ldots\end{array}$ & $54(20 / 61)$ & $19(39 / 207)$ & $18(10 / 57)$ & $20(66 / 325)$ \\
\hline Total & $42 *(74 / 176)$ & $42(45 / 106)$ & $21(4 / 19)$ & $43(69 / 162)$ \\
& & $30(65 / 217)$ & $25(16 / 65)$ & $29(96 / 326)$ \\
\hline
\end{tabular}

*Difference between proportions for $(a)$ inpatients and $(b)$ outpatients and general practice referrals is significant $(P<0.01)$.

\section{HAEMATURIA}

For the 156 patients who underwent urography because of haematuria four categories of evidence were first defined: (1) red cells present in a midstream urine specimen, (2) a frank history of haematuria where a midstream specimen was either not taken or showed no red cells, (3) occult blood identified in a urine specimen by a general practitioner or a nurse in the ward, and (4) no history or laboratory evidence of haematuria recorded in the case notes.

Urograms from those with the strongest evidence of haematuria were about twice as likely to show-abnormalities as urograms from those with less strong evidence ( $71 \%$ abnormal compared with $34 \%, 38 \%$, and $42 \%$ abnormal) (table IV). In addition the likelihood of undergoing cystoscopy and the proportions with abnormal cystoscopic findings (especially of the bladder) were again highest in those with the strongest clinical evidence of haematuria.
TABLE IV-Percentage of Abnormal Urograms According to Strength of Evidence for Haematuria* (Numbers of Urograms are Given in Parentheses)

\begin{tabular}{l|c|c|c|c}
\hline $\begin{array}{l}\text { Category of haematuria* } \\
\% \text { (No.) of abnormal urograms... }\end{array}$ & $71(37 / 52)$ & $34 \underset{(21 / 62)}{2}$ & $38(3 / 8)$ & $42(8 / 19)$
\end{tabular}

*See text for definitions.

One-third of the patients with carcinoma of the bladder had normal urograms.

\section{HYPERTENSION}

Only $6(5 \%)$ of the 130 hypertensive patients investigated by urography had renal abnormalities which might have had a causal role in their hypertension (table V). The results of other tests in these six patients are given in table VI; all had either an abnormality on a straight abdominal radiograph or raised blood urea concentration or a pathogenic organism detected in a midstream specimen of urine.

TABLE v-Radiological Abnormalities in 130 Patients Having Urography for Investigation of Hypertension

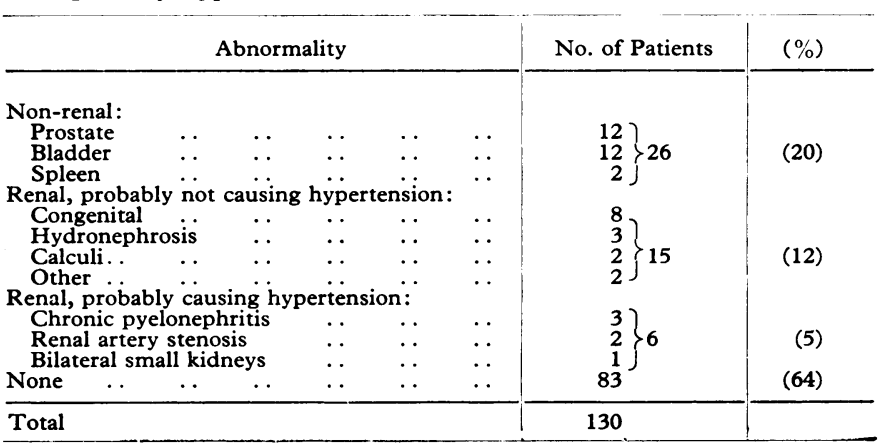

TABLE VI-Results of Urography and Other Investigations in Six Patients with Renal Causes for Hypertension

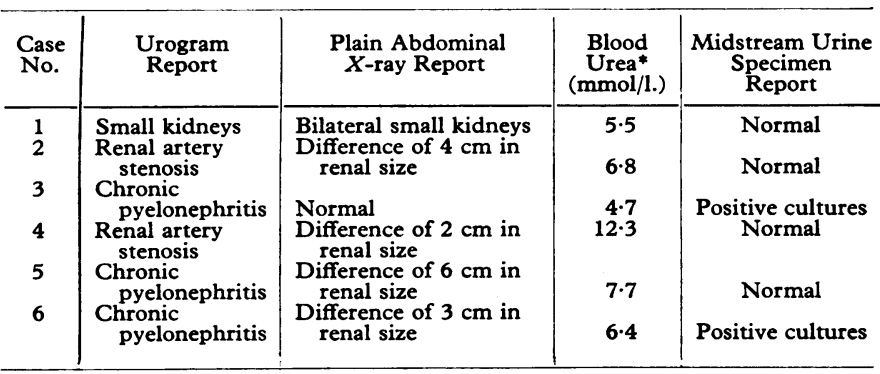

*Upper limit of "normal" range at Northwick Park $6.5 \mathrm{mmol} / \mathrm{l}$.

\section{Discussion}

The methods used in this study clearly have limitations. Firstly, the radiological reports, not the films themselves, were used to classify results as normal and abnormal, and the classification was made by only one observer. All films and reports at Northwick Park, however, are checked by a consultant radiologist and doubtful cases are usually discussed with the clinicians concerned before a final report is issued; this procedure enables most reports to be made in unequivocal terms. We therefore expected that interobserver variability would be low; a small initial comparison between two observers indicated that this was indeed the case, virtually no disagreements being noted. Secondly, differences in case-mix (that is, the variations between doctors in the proportions of their patients with different symptoms, diagnoses, sources of referal, etc.) between different doctors could account for some of the variations in the proportions of abnormal results (see, for example, tables II 
and III). Analysis of the results by individual reasons for requesting a urogram, however, does toa greater or less extent (depending on the specificity of the symptoms and signs concerned) go some way towards meeting this objection. In addition, the identification of general situations associated with relatively low abnormality proportions-for example, general practice and outpatient referrals for urograms (table II)-may suggest ways, not depending too greatly on case-mix by which attempts can be made to reduce the numbers of unproductive requests. The method described does at least give the radiologist comparative data as a starting point for consultation with different clinicians on the ways in which they use his service; variations in case-mix may be one possible explanation emerging from discussions of this sort.

The point is also made that a normal urogram may be as valuable as an abnormal one. This is often true, but not necessarily always. Our results and those of Atkinson and Kellett ${ }^{4}$ suggest that a normal urogram may contribute little to the investigation of hypertension since most of its renal causes are suspected if not precisely identified by the use of other and less costly methods. On the other hand, in some situations tests other than urography will not distinguish between those with and those without a particular condition, and in these cases a normal urogram is obviously of real diagnostic value. This point is illustrated in table VII, which gives the findings in a consecutive series of 65 surgical outpatients with prostatism in whom urography was requested specifically in order to determine any backpressure effects. (The figures in table II refer to all requests for evidence of prostatism.) Clearly an increase of the blood urea level above "normal" does not discriminate between the presence and absence of back-pressure effects.

TABLE VII-Presence or Absence of Back-pressure Effects on Kidneys and Ureters and Bladder by Urography and Initial Blood Urea Level

\begin{tabular}{|c|c|c|c|c|c|}
\hline \multirow{3}{*}{\multicolumn{2}{|c|}{ Urography }} & \multicolumn{4}{|c|}{ Blood Urea Level } \\
\hline & & \multicolumn{2}{|c|}{$0-6.5 \mathrm{mmol} / 1$} & \multicolumn{2}{|c|}{ Over $6.5 \mathrm{mmol} / \mathrm{l}$} \\
\hline & & No. & $\%$ & No. & $\%$ \\
\hline \multicolumn{6}{|c|}{ Kidneys and Ureters } \\
\hline 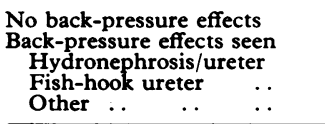 & $\begin{array}{l}\ldots \\
\cdots \\
\cdots \\
\cdots\end{array}$ & $\begin{array}{rr}28 & \\
18 & \\
3 \\
8 \\
7\end{array}$ & $\begin{array}{r}61 \\
39 \\
7 \\
17 \\
15\end{array}$ & $\begin{array}{rr}11 \\
8 \\
3 \\
5 \\
\\
0\end{array}$ & $\begin{array}{r}58 \\
42 \\
16 \\
26 \\
0\end{array}$ \\
\hline Total & & 46 & 100 & 19 & 100 \\
\hline \multicolumn{6}{|c|}{ Bladder } \\
\hline $\begin{array}{l}\text { No back-pressure effects } \\
\text { Back-pressure effects seen } \\
\text { (trabeculation and/or residu } \\
\text { urine) } \ldots\end{array}$ & $\begin{array}{c}\cdots \\
\text { alal } \\
\cdots\end{array}$ & 15 & $\begin{array}{l}33 \\
67\end{array}$ & $\begin{array}{r}6 \\
13\end{array}$ & $\begin{array}{l}32 \\
68\end{array}$ \\
\hline Total & & 46 & 100 & 19 & 100 \\
\hline
\end{tabular}

There is obviously no absolute rule or convention that can be derived. If the clinician thinks a particular investigation is necessary he will (and must) ask for it because of his overriding responsibility to the patient and not on the basis of a probability that it may or may not be helpful. Nevertheless, it is increasingly clear, if also unpalatable, that the use of one resource for some patients denies the use of the same or a different one for others (often, perhaps, patients under the care of the same clinician). The undoubted value of the normal urogram would remain and at the same time unproductive examinations could be reduced if, as with hypertension, for example, other appropriate investigations were carried out and their results considered before the urogram was requested.

Finally, it may be claimed that we have not discussed the extent to which patients with renal disease were investigated without urography. We think this is likely to be small; for instance, a sample taken from Hospital Activity Analysis at Northwick Park showed that $90 \%$ of inpatients with hypertension as the primary diagnosis at the time of our study had undergone urography (though very few do now). In any case our study deals primarily with the radiologist's work load and the use to which clinicians put his facilities.

Advantages of this approach are, firstly, its simplicity. It could be set up at very little extra cost. Secondly, together with other studies, such as those of Atkinson and Kellett, ${ }^{4}$ some findings can probably already be used to consider ways in which urograms may be used more effectively than hitherto. These are listed below.

(1) The considerably higher proportion of normal urograms from outpatients and patients referred from general practice than from inpatients, added to the fact that well over half of all urograms are requested from the outpatient department and general practice, indicates that it is in these groups that attempts to reduce potentially uninformative examinations may best be made. If, however, it is accepted that a high proportion of patients being investigated for possible renal and urinary tract disease will undergo urography it is clearly preferable that normal findings should be established on an outpatient rather than an inpatient basis.

(2) The lack of confirmatory clinical or laboratory evidence in $18 \%$ of the hospital requests arising from haematuria coupled with the other findings presented raises doubts that haematuria had really occurred. A considerable saving in radiological resources might be made by ensuring that in cases of this sort a midstream specimen of urine is examined followed by cystoscopy; judged by the high proportion of normal radiological findings in patients with bladder tumours cystoscopy is clearly as important diagnostically as urography, if not more so.

(3) Most renal causes of hypertension can be detected without urography by using other methods (such as renography) in conjunction with plain abdominal films, urine examination, and blood urea estimations. As with haematuria there seems to be considerable scope for rationalizing which tests should be used and the order in which they are carried out.

We conclude, therefore, that the simple method described makes it possible to suggest ways in which the effective use of urography may be increased, particularly by the appropriate use of other investigations.

We wish to thank the many doctors at Northwick Park who commented on and helped with this work at various stages.

Requests for reprints to T.W.M.

\section{References}

1 Ashley, J. S. A., Pasker, P., and Beresford, J. C., Lancet, 1972, 1, 890. 2 Department of Health and Social Security, Digest of Health Statistics London, H.M.S.O., 1971.

3 Bull, J. W. D., and Zilkha, K. J., British Medical fournal, 1968, 4, 569.

4 Atkinson, A. B., and Kellett, R. J., fournal of the Royal College of Physicians of London, 1974, 8, 175 . 